\title{
A new mechanism of gastroesophageal reflux in hiatal hernia documented by high-resolution impedance manometry: a case report
}

\author{
Francesco Torresan, Daniele Mandolesi, Alexandros loannou, Simone Nicoletti, \\ Leonardo Henry Eusebi, Franco Bazzoli
}

University of Bologna, Italy

\section{Abstract}

\begin{abstract}
Gastroesophageal reflux disease (GERD) is recognized to be a multifactorial disease and several mechanisms leading to reflux have been described, nevertheless its pathophysiology has not been fully clarified. Hiatus hernia is a known risk factor for GERD since it impairs the esophagogastric junction, leading to: reduction in lower esophageal sphincter pressure; increase in the frequency of the transient lower esophageal sphincter relaxation; and impairment of esophageal clearance. Last generation diagnostic techniques have improved the understanding of these mechanisms. A 72-year-old woman with hiatus hernia and GERD underwent a high resolution impedance manometry (HRIM) after a partial response to treatment with pantoprazole. None of the proposed pathophysiological mechanisms for GERD could explain the presence of reflux: HRIM showed normal lower esophageal sphincter (LES) pressure and contractile integral, complete bolus clearance in all test swallows, and absence of transient LES relaxation. However, after the end of each peristaltic wave, as the LES pressure returned to resting values, a gastroesophageal reflux was detected until the following swallow. We describe an interesting case of a patient with a sliding hiatus hernia, with symptoms suggestive of GERD, in which HRIM revealed a new possible mechanism through which hiatus hernia may lead to GERD.
\end{abstract}

Keywords Gastroesophageal reflux disease, hiatus hernia, high resolution impedance manometry

Ann Gastroenterol 2016; 29 (3): 1-3

\section{Introduction}

Hiatus hernia $(\mathrm{HH})$ interferes with the anatomy and physiology of the normal anti-reflux barrier through several mechanisms, such as: reduction in lower esophageal sphincter (LES) pressure; increase in the frequency of the transient LES relaxation (TLESR); and impairment of esophageal clearance [1]. Another proposed mechanism by which $\mathrm{HH}$ leads to GERD is that gastric content gets trapped in the hernial sac (between LES and crural diaphragm, CD), and subsequently refluxes during swallow-induced relaxations of the LES [2]. Recently, high resolution impedance manometry (HRIM) has been introduced to combine the benefits of high resolution manometry and impedance-based bolus transit assessment.

Gastroenterology Unit, Department of Medical and Surgical Sciences, University of Bologna, Italy

\section{Conflict of Interest: None}

Correspondence to: Dr. Daniele Mandolesi, Department of Medical and Surgical Sciences, Policlinico S. Orsola,

Via Massarenti 9, 40138 Bologna, Italy, Tel./Fax: +39 0516363376, e-mail: dani.mandolesi@gmail.com

Received 24 March 2016; accepted 19 May 2016 published online 10 June 2016

DOI: http://dx.doi.org/10.20524/aog.2016.0055
We herein report the case of a patient presenting with heartburn, acid regurgitation and hoarseness, in which HRIM revealed a new possible mechanism by which $\mathrm{HH}$ leads to GERD even with normal basal LES pressure, without TLESRs and normal esophageal clearance.

\section{Case report}

A 72-year-old woman was referred to our clinic due to heartburn, acid regurgitation and hoarseness during the last year. One year before the admission, at the beginning of her symptoms, the patient underwent an upper endoscopy and a barium esophagogram, showing a 4 -cm long sliding $\mathrm{HH}$, with a grade B esophagitis according to Los Angeles classification. Her primary care physician started treatment with pantoprazole $40 \mathrm{mg}$ b.i.d. with only partial symptom improvement. Thus, before considering $\mathrm{HH}$ surgical repair, she was sent to our center for further investigations.

A HRIM was performed using a solid-state manometric assembly with 36 circumferential sensors spaced at $1 \mathrm{~cm}$ with an intraluminal impedance monitoring (Sierra Scientific Instruments Inc., Los Angeles, CA.) and 18 impedance segments at $2-\mathrm{cm}$ intervals. The study was performed after at least $6-\mathrm{h}$ fasting and according to the standard procedure based on 
10 water swallows in supine position, including a 30 -sec period to assess basal sphincter pressure. The results of HRIM are summarized in Table 1. Manometric study showed that basal LES pressure was $23.7 \mathrm{mmHg}$ (normal values: $13-43 \mathrm{mmHg}$ ). The integrated relaxation pressure $(6.9 \mathrm{mmHg} ; \mathrm{N}:<15 \mathrm{mmHg}$ ) and the mean distal contractile integral $(3272.1 \mathrm{mmHg}-\mathrm{cm}-\mathrm{sec} ; \mathrm{N}$ : 500-5000 mmHg-cm-sec) were normal. The study of esophageal motility demonstrated peristaltic waves in 9/10 swallows (90\%); double-peaked waves were detected in $3 / 10(30 \%$; $: \leq 15)$. The intrabolus pressure was significantly higher than the normal value $(41 \mathrm{mmHg}-\mathrm{N}$ : <17). No TLESRs were detected.

Impedance results demonstrated an effective peristalsis, with $100 \%$ swallowing with complete bolus transit (10/10 swallows) and confirmed a complete bolus clearance in each swallow. All the swallow phases were studied: at first the synchronized opening of both the upper and lower esophageal sphincters, which provided the complete clearance of the esophagus, then the peristaltic progression of the bolus through the esophageal body and finally the closure of the LES, once the bolus was passed in the gastric compartment.

In our patient, few seconds after the end of each peristaltic wave, as the LES pressure recovered its resting value and after the complete esophageal clearance, a gastroesophageal reflux was detected until the following swallow, which provided the complete clearance of the esophagus after the swallow-induced opening of the LES (Fig. 1,2).

Table 1 High-resolution impedance manometry findings

\begin{tabular}{|c|c|c|}
\hline Parameter & Value & $\begin{array}{l}\text { Normal } \\
\text { values }\end{array}$ \\
\hline $\begin{array}{l}\text { Lower esophageal sphincter } \\
\text { LES length }(\mathrm{cm})\end{array}$ & 1.7 & $2.7-4.8$ \\
\hline LES pressure $(\mathrm{mmHg})$ & 13.7 & $13-43$ \\
\hline Integrated relaxation pressure $(\mathrm{mmHg})$ & 6.9 & $<15$ \\
\hline \multicolumn{3}{|l|}{ Body peristalsis } \\
\hline $\begin{array}{l}\text { Peristaltic contractions } \\
\text { (speed } \geq 6.25 \mathrm{~cm} / \mathrm{sec})(\%)\end{array}$ & 90 & $\geq 80$ \\
\hline $\begin{array}{l}\text { Simultaneous contractions } \\
\text { (speed } \geq 6.25 \mathrm{~cm} / \mathrm{sec} \text { ) (\%) }\end{array}$ & 10 & $\leq 20$ \\
\hline Ineffective & 0 & 0 \\
\hline Wave mean duration (sec) & 5.4 & $2.7-5.4$ \\
\hline Double-peaked waves (\%) & 30 & $\leq 15$ \\
\hline \multicolumn{3}{|l|}{ High resolution parameters } \\
\hline $\begin{array}{l}\text { Distal contractile integral (mean) } \\
\text { (mmHg-cm-sec) }\end{array}$ & 3272,1 & $500-5000$ \\
\hline $\begin{array}{l}\text { Intrabolus pressure (mean max) } \\
(\mathrm{mmHg})\end{array}$ & 41 & $<17$ \\
\hline $\begin{array}{l}\text { Distal latency (sec) } \\
\text { Swallows with compartmentalized } \\
\text { pressurization }(\%)\end{array}$ & $\begin{array}{c}6.3 \\
0\end{array}$ & $>4.5$ \\
\hline \multicolumn{3}{|l|}{ Impedance analysis } \\
\hline Incomplete bolus clearance (n) & 0 & - \\
\hline
\end{tabular}

LES, lower esophageal sphincter

\section{Discussion}

$\mathrm{HH}$ causes an anatomical and physiological interference in the normal anti-reflux barrier with several mechanisms: it reduces LES length and pressure, impairs the augmenting effects of the diaphragmatic crus, is associated with decreased esophageal peristalsis, increases the cross-sectional area of the esophagogastric junction (EGJ), and acts as a reservoir allowing reflux from the hernial sac into the esophagus during swallowing [1]. All these mechanisms lead to: reduction in LES competence; increase in the frequency of the acid-associated TLESRs; and impairment of esophageal clearance [3-5].

However, the relation between TLESRs and reflux has been already redefined in the last years: several studies showed that TLESRs are not more frequent in patients with GERD than in age- and sex-matched asymptomatic volunteers, however, when TLESRs occur in patients, they are twice as likely to be associated with acid reflux [9]. Moreover, Van Herwaarden et al showed that the majority of the reflux episodes occur during a TLESR in patients without $\mathrm{HH}$, while in the presence of $\mathrm{HH}$ other mechanisms may play a determinant role $[8,10]$.

HRIM studies introduced interesting data about EGJ morphology, highlighting a possible axial separation between LES and CD. This event can be interpreted as the presence of $\mathrm{HH}$, or, more precisely, as an anatomical disruption of EGJ, leading to a reduction in its physiological anti-reflux barrier activity. On this basis, EGJ was classified into three types: type I (no LESCD separation); type II (LES and CD are spatially separated such that there is a double-peaked pressure profile); and type III (the separation between peaks is $>2 \mathrm{~cm}$ ). Recently, Tolone et al demonstrated that the increasing separation between LES and CD, from type I to type III EGJ, is associated with a significant increase in reflux episodes, esophageal acid exposure time and positive reflux-symptom association $[11,12]$. These considerations have been applied in the evaluation of the LES contractile integral, whose defective values seem to show a gradual and significant increase in reflux. However, further studies are needed to explore its utility in the management of GERD $[6,7]$.

It has been supposed, but never demonstrated, that the increasing pressure in the hernial sac could also be another important component; Mittal et al [2] proposed that gastric content trapped in the $\mathrm{HH}$ sac could reflux during subsequent swallow-induced relaxations of the LES.

The case we described is particularly interesting since none of the proposed mechanisms could explain the presence of reflux showed by the use of HRIM. Not only the LES pressure, but also the contractile integral was normal. The HRIM evaluation also showed complete bolus clearance in all test swallows and the absence of TLESRs. However, after the end of each peristaltic wave, as the LES pressure returned to resting values, a gastroesophageal reflux was detected until the following swallow.

The most probable hypothesis could be that reflux is due to a transient increase in hernial sac pressure: the hernial sac acts as a reservoir increasing its pressure to overcome the basal LES pressure. As a consequence, the gastric content could reflux from the hernial sac into the esophagus, not during swallowing phase like Gordon et al [1] proposed, but after the end of each peristaltic wave until the following swallow. The mechanism 


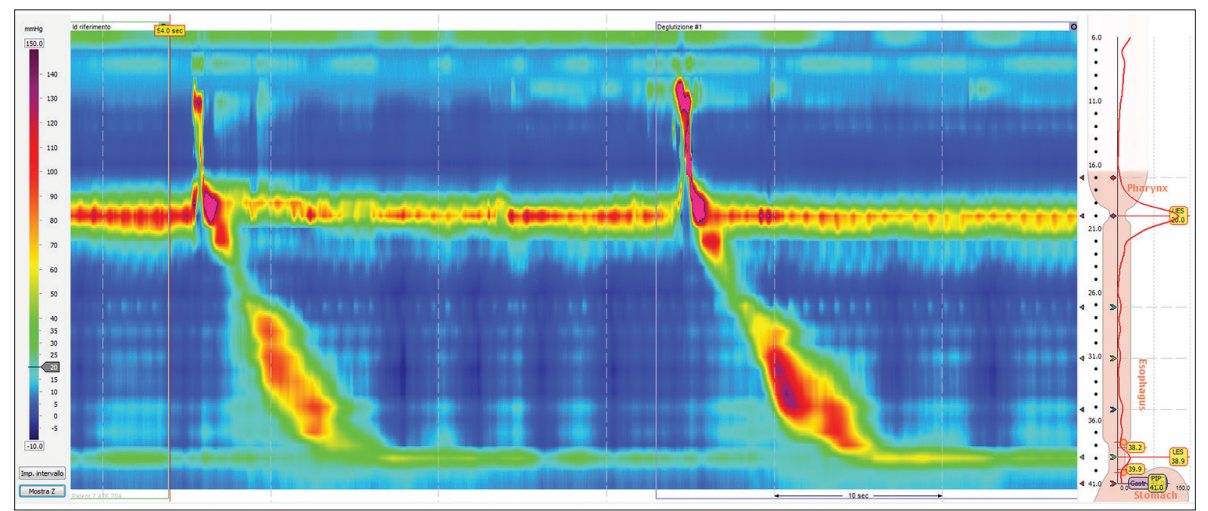

Figure 1 High resolution manometry shows normal basal lower esophageal sphincter (LES) pressure, normal esophageal peristalsis waves and no transient LES relaxations

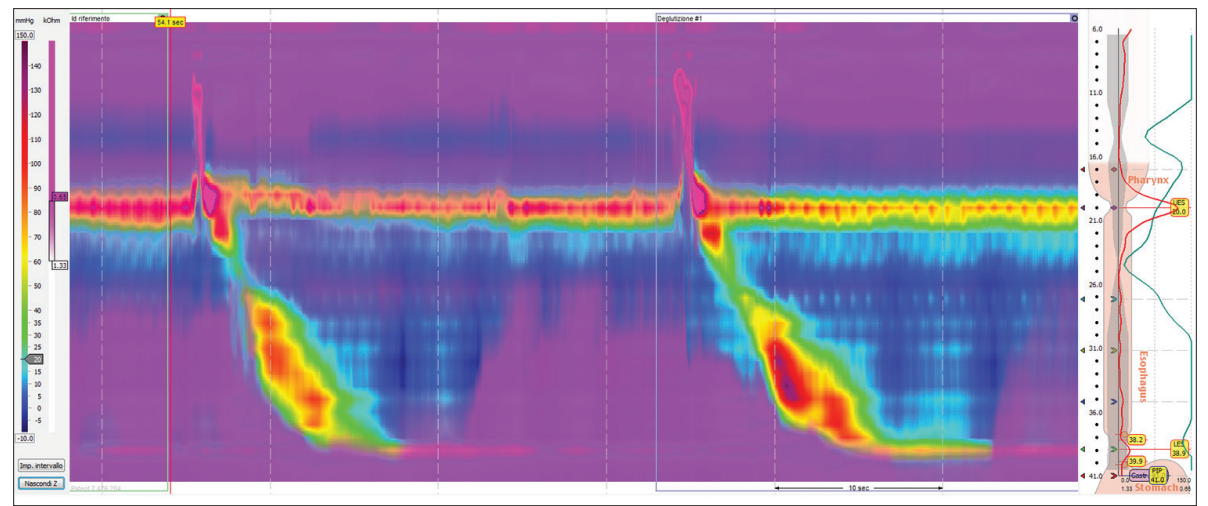

Figure 2 The impedance study shows the complete bolus clearance and the gastroesophageal reflux until the following swallow

we have described may be similar to what happens in the acid pocket of patients with $\mathrm{HH}$, with the difference that in our case reflux occurs even in absence of TLESRs and with a perfectly working LES, despite $\mathrm{HH}$. The advent of new generation technologies, like HRIM, has allowed a more accurate and precise assessment of the EGJ and its increasing use could open to new considerations on the pathophysiology of GERD.

\section{References}

1. Gordon C, Kang JY, Neild PJ, Maxwell JD. The role of the hiatus hernia in gastro-oesophageal reflux disease. Aliment Pharmacol Ther 2004;20:719-732.

2. Mittal RK, Lange RC, McCallum RW. Identification and mechanism of delayed esophageal acid clearance in subjects with hiatus hernia. Gastroenterology 1987;92:130-135.

3. Sifrim D, Holloway R, Silny J, Tack J, Lerut A, Janssens J. Composition of the postprandial refluxate in patients with gastroesophageal reflux disease. Am J Gastroenterol 2001;96:647-655.

4. Trudgill NJ, Riley SA. Transient lower esophageal sphincter relaxations are no more frequent in patients with gastroesophageal reflux disease than in asymptomatic volunteers. Am J Gastroenterol 2001;96:2569-2574.

5. Jones MP, Sloan SS, Jovanovic B, Kahrilas PJ. Impaired egress rather than increased access: an important independent predictor of erosiveoesophagitis. Neurogastroenterol Motil 2002;14:625-631.

6. Nicodeme F, Pipa-Muniz M, Khanna K, Kahrilas PJ, Pandolfino JE. Quantifying esophagogastric junction contractility with a novel HRM topographic metric, the EGJ-Contractile Integral: normative values and preliminary evaluation in PPI non-responders. Neurogastroenterol Motil 2014;26:353-360.

7. Hoshino M, Sundaram A, Mittal SK. Role of the lower esophageal sphincter on acid exposure revisited with high-resolution manometry. J Am Coll Surg 2011;213:743-750.

8. Bredenoord AJ, Weusten BL, Timmer R, Smout AJ. Intermittent spatial separation of diaphragm and lower esophageal sphincter favors acidic and weakly acidic reflux. Gastroenterology 2006;130:334-340.

9. Herregods TV, Bredenoord AJ, Smout AJ. Pathophysiology of gastroesophageal reflux disease: new understanding in a new era. Neurogastroenterol Motil 2015;27:1202-1213.

10. Van Herwaarden MA, Samsom M, Smout AJ. Excess gastroesophageal reflux in patients with hiatus hernia is caused by mechanisms other than transiet LES relaxations. Gastroenterology 2000;119:1439-1446.

11. Tolone S, De Bortoli N, Marabotto E, et al. Esophagogastric junction contractility for clinical assessment in patients with GERD: a real added value? Neurogastroenterol Motil 2015;27:1423-1431.

12. Tolone S, De Cassan C, De Bortoli N, et al. Esophagogastric junction morphology is associated with positive impedance$\mathrm{pH}$ monitoring in patients with GERD. Neurogastroenterol Motil 2015;27:1175-1182. 